\title{
INFÂNCIA SAUDÁVEL: Educação em Saúde nas Escolas
}

\author{
HEALTHY CHILDHOOD: Health Education in Schools
}

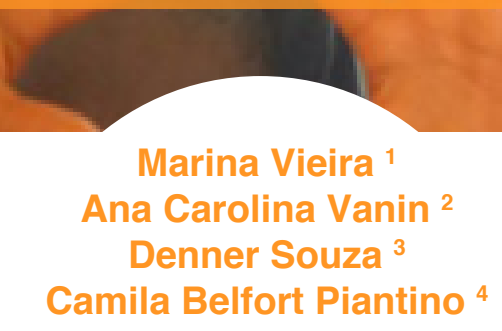

RESUMO

O conceito de educação em saúde está atrelado à melhoria da qualidade de vida e a prevenção de doenças. O objetivo do projeto foi favorecer o desenvolvimento de ações educativas junto a escolares da educação infantil. Ações vinculadas às temáticas: saúde bucal, higiene pessoal e higienização dos alimentos foram desenvolvidas de forma lúdica. Funcionários foram orientados sobre a limpeza e desinfecção dos ambientes, equipamentos e utensílios, acondicionamento e destino do lixo. Ressalta-se que a importância de se trabalhar com escolares de 6 a 9 anos encontra-se atrelada ao desenvolvimento da necessidade de higiene pessoal e adequação a novos hábitos de vida, pois, é este o período em que a criança desenvolve sua personalidade, o que poderá contribuir para aquisição de atitudes mais saudáveis.

Palavras chave: Educação em saúde. Qualidade de vida. Infância saudável.

\section{ABSTRACT}

The concept of health education is linked to the improvement of the quality of life and the prevention of diseases. The objective of the project was to favour the development of educational actions with children's education students. Actions linked to the themes: oral health, personal hygiene and hy-

\footnotetext{
${ }^{1}$ Universidade do Estado de Minas Gerais. E-mail: marinavieirans@gmail.com

${ }^{2}$ Universidade do Estado de Minas Gerais. E-mail: carol.vanin@outlook.com

${ }^{3}$ Universidade do Estado de Minas Gerais. E-mail: dennerh.souza@outlook.com

${ }^{4}$ Doutora em Ciências da Saúde e Professora do Núcleo de Saúde da Universidade do Estado de Minas Gerais. E-mail: camilapiantino@hotmail.com
} 
giene of foods were developed in a playful way. Staffs were advisedon the cleaning and disinfection of environments, equipment and utensils, packaging and disposal of garbage. It is important to notice that the importance of working with schoolchildren aged from 6 to 9 years is linked to the development of the need for personal hygiene and adaptation to new habits of life, since this is the period in which the child develops his/her personality, which may contribute to the acquisition of healthier attitudes.

Keywords: Health education. Quality of life. Healthy childhood.

\section{INTRODUÇÃO}

O conceito de educação em saúde está atrelado a um conjunto de "regras" que contribuem para a melhoria da qualidade de vida, bem como para a prevenção de doenças. A esta definição agrega-se o conhecimento por ser o método mais eficiente para se assimilar e corrigir as necessidades, possibilitando mudanças comportamentais tendo em vista a prática como efetivação dessa mudança (MINISTÉRIO DA SAÚDE, 1998 apud OLIVEIRA; GONÇALVES, 2004).

Sob o ponto de vista do processo saúde/doença, as suas múltiplas dimensões, por si só, justificam a opção de caracterizar a educação para a saúde como um tema transversal do currículo. Com efeito, somente a participação das diferentes áreas, cada qual enfocando conhecimentos específicos à sua competência, pode garantir que os alunos construam uma visão ampla do que é saúde justificando a atuação de acadêmicos de cursos da área da saúde junto a escolares do ensino fundamental com o intuito de se construir vínculos e pactuar ações tanto no campo preventivo, quanto no de promoção da saúde.

\section{FUNDAMENTAÇÃO TEÓRICA}

Ações voltadas à promoção da saúde e práticas de vida saudáveis podem ser beneficiadas pelo processo de educação em saúde, onde se oportuniza o compartilhamento de saberes dos mais variados possíveis na busca de soluções das mais diversas problemáticas.

Segundo Costa et al. (2008), ações educativas podem visar à sensibilização e/ou a conscientização sobre algum problema de saúde, ou ações que possam evitar o surgimento de males à clientela. Nesse sentido, não se pode deixar de lembrar o quanto às ações preventivas são mais vantajosas que as ações curativistas; tanto do ponto de vista econômico, quanto do ponto de vista assistencial, uma vez que podem reduzir a 
incidência de doenças e contribuir para a diminuição do número de pacientes que buscam serviços de maior complexidade, mais dispendiosos e por vezes menos efetivos.

Considerando-se a evolução histórica do espaço escolar como um campo de promoção da saúde, nos últimos 30 anos, o trabalho educativo em saúde, vivenciado na escola, avançou consideravelmente no país, favorecendo a articulação entre a saúde e a educação nos espaços institucionais (COSTA et al., 2013). Trata-se de uma iniciativa já difundida em alguns países e que vem se desenvolvendo lentamente em escolas brasileiras. A análise dos antecedentes históricos da promoção da saúde em escolas nos remete ao seu país de origem, o Canadá,no qual a partir da década de 1970, configurou as bases internacionais do ideário da escola enquanto cenário promotor de saúde (VALADÃO, 2004). Experiência realizada na China demonstra, ainda, que modelos de atenção pautados nos aspectos ambientais da saúde estão articulados a melhores resultados (VALADÃO, 2004).

Atualmente o conceito de promoção da saúde está vinculado à compreensão de que saúde não é apenas a ausência de doença, sua definição insere-se a uma rede complexa de interdependências e inter-relações na qual não é possível estabelecer uma causalidade linear (FRAGA et al., 2013). Diante deste contexto, nota-se ainda que o incremento da violência, a pobreza e a desestruturação familiar comprometem os resultados do processo de aprendizado escolar. A escola atual não é apenas um local onde se ensina matemática, biologia e línguas, mas também um centro de multiplicação de informações sobre prevenção de acidentes, hábitos de higiene, abuso de drogas e outros temas de relevância. É importante que o aluno seja visto de forma integral uma vez que o aspecto biopsicossocial do mesmo passa a influenciar de forma decisiva sobre seu aprendizado (LIBERAL,2002).

A escola é um ambiente propício para o desenvolvimento de ações educativas em saúde visto que nela se constrói, destrói ou se perpetua uma ideologia através da transmissão de valores e crenças. Diante da abordagem de pré-escolares ressalta-se ainda que na infância ocorre a construção e solidificação dos hábitos e atitudes e, em vista disso, destaca-se a importância do papel da escola como um ambiente potencializador para o desenvolvimento de um trabalho direcionado (HARADA et al.,2013). Gardanoet al. (2013) destaca ainda que a concretização de projetos de promoção da saúde (PS) no contexto escolar está apoiada no professor, o qual representa um elo importante e fundamental neste contexto, sendo um multiplicador de ideias.

Ações educativas vinculadas à temática "cuidados básicos de higiene para prevenção de doenças e manutenção da saúde" são de fácil execução e podem contribuir para redução de doenças infectocontagiosas, 
mais frequentes em crianças em ambientes escolares. A orientação e treinamento dos funcionários, responsáveis pela manipulação e higienização dos alimentos, serviços básicos de desinfecção de áreas de acesso comum se faz indispensável neste processo (BRASIL, 2008).

A criança é vista como um indivíduo em desenvolvimento fisiológico e funcional, exposto asituações de risco na medida em que interage constantemente com situações e organismos até então desconhecidos.Assim, não é raro o surgimento de agravos à saúde, pois essa interação possibilita o aparecimento de patologias que se relacionam com os contextos nos quais as crianças estão inseridas. Doenças como desnutrição infantil, infecções respiratórias, doenças infectocontagiosas, dentre outras, ocorrem constantemente (SOUZA et al.,2013).

Diante do exposto, verifica-se a relevância da prática de ações educativas, sob o ponto de vista do processo saúde/doença. Sendo assim, propõe-se o desenvolvimento de ações educativas vinculadas à temática "cuidados básicos de higiene para prevenção de doenças e manutenção da saúde", considerando a escola como cenário favorável, e a comunidade escolar (alunos, educadores e famílias) como público para PS, estimulando-o a assumir atitudes mais saudáveis.

\section{METODOLOGIA}

O projeto de extensão "INFÂNCIA SAUDÁVEL: Educação em Saúde nas Escolas" foi desenvolvido por dois acadêmicos bolsistas do Programa de Apoio a Extensão da Universidade do Estado de Minas Gerais (PAEx) e um acadêmico voluntário do curso de biomedicina os quais receberam treinamento e supervisão da coordenadora envolvida.

O projeto foi desenvolvido em três escolas públicas municipais de educação infantil de um município do Sudoeste mineiro. Para inclusão das escolas participantes, a equipe de extensionistas entrou em contato com a direção para apresentação da proposta de trabalho e articulação da disponibilidade de horários semanais nas turmas abrangidas pela extensão, escolares de 6 a 9 anos, visto que englobam a faixa etária que mais se identifica com a temática proposta. Foram contemplados cerca de 110 alunos da rede pública municipal de ensino.

Reuniões entre os extensionistas para a avaliação, repasse e planejamento das atividades foram realizadas semanalmente. Todas as atividades eram devidamente acompanhadas através de relatórios mensais entregues ao orientador. Coube aos acadêmicos a organização das reuniões e atividades de campo. 
O contato inicial com os alunos consistiu na apresentação do projeto de extensão e de seus temas. Com isto, montou-se um cronograma de atividades de acordo com a disponibilidade de cada escola (Tabela 1). As atividades foram norteadas pela temática "cuidados básicos de higiene para prevenção de doenças e manutenção da saúde", foram organizadas aulas, dinâmicas e discussões informais com os alunos, em sala de aula bem como ações globais, que envolveram palestras e gincanas. As ações desenvolvidas foram pautadas no álbum O que é Vida Saudável? de autoria do Ministério da Saúde publicado em 2008. Vídeos, materiais informativos, cartazes, fantoches foram selecionados para que a interação entre acadêmicos e os escolares ocorresse de forma lúdica. As temáticas foram trabalhadas separadamente em três encontros semanais de 1 h30 durante um mês.

Tentou-se organizar juntamente com a direção da escola encontros com os pais de alunos, para apresentação do projeto e realização de palestras. Infelizmente, devido a pouca capacidade de mobilização junto ao corpo de pais e ou pela falta de cultura de participação dos mesmos nas atividades ofertadas pelas escolas não foi possível obter estes encontros.

Tabela 1 - Descrição das atividades desenvolvidas com os escolares. Passos, (2016).

\begin{tabular}{|c|c|l|c|}
\hline Temática & Intervenção & Atividades desenvolvidas & Período \\
\hline Higiene bucal & Palestra/Oficina & $\begin{array}{l}\text { - Técnica de escovação } \\
\text { - Vídeos educativos } \\
\text { - Confecção de cartazes }\end{array}$ & Mês 1 \\
\hline $\begin{array}{c}\text { Higiene pessoal } \\
\text { Palestra/Oficina }\end{array}$ & $\begin{array}{l}\text { - Técnica de higienização das mãos } \\
\text { - Vídeos educativos }\end{array}$ & Mês 2 \\
\hline $\begin{array}{c}\text { Higienização dos } \\
\text { alimentos }\end{array}$ & Palestra & Desinfecção dos alimentos & Mês 3 \\
\hline
\end{tabular}

Fonte: Dados do projeto "Infância Saudável: Educação em Saúde nas Escolas”, 2016. Fonte: VIEIRA, M.

\section{ATIVIDADE DESENVOLVIDA COM OS FUNCIONÁRIOS}

Ações vinculadas às temáticas, destino e acondicionamento do lixo, limpeza e desinfecção de ambientes foram elaboradas pelos acadêmicos 
sob supervisão do professor orientador. As atividades foram desenvolvidas para os funcionários responsáveis pelos serviços gerais das escolas. As atividades educativas ocorreram em dois encontros e foram desempenhadas por meio de roda de conversa e oficina, utilizou-se como recurso material o projetor multimídia a fim de elucidar as temáticas com figuras ilustrativas e vídeos.

\section{RESULTADOS}

A princípio, a equipe extensionista entrou em contato com as escolas da rede pública municipal por telefone, em seguida marcaram encontros para apresentação da proposta. As escolas que se interessaram em receber o projeto agendaram com a equipe as datas e horários de acordo com sua disponibilidade.

$\mathrm{Na}$ primeira escola, o projeto teve duração de três meses, os encontros se deram três vezes por semana. Foram duas turmas de alunos A e B, Turma A: escolares de 6 à 8 e turma B: 8 à 10 anos. Às segundasfeiras e terças-feiras eram ministradas palestras para as Turmas A e B respectivamente cujas temáticas foram descritas na Tabela 1. Às quartas-feiras a equipe desenvolvia oficinas com as duas turmas sobre os temas abordados nas palestras, como estratégia para fixação do conteúdo abordado. Oficinas foram realizadas para cada tema trabalhado e, ao final, procedeu-se com uma gincana composta de perguntas relacionadas aos temas visando à análise da assimilação do conteúdo trabalhado junto às crianças. Algumas das atividades encontram-se registradas nas fotografias a seguir (Figura 1, Figura 2 e Figura 3 ).

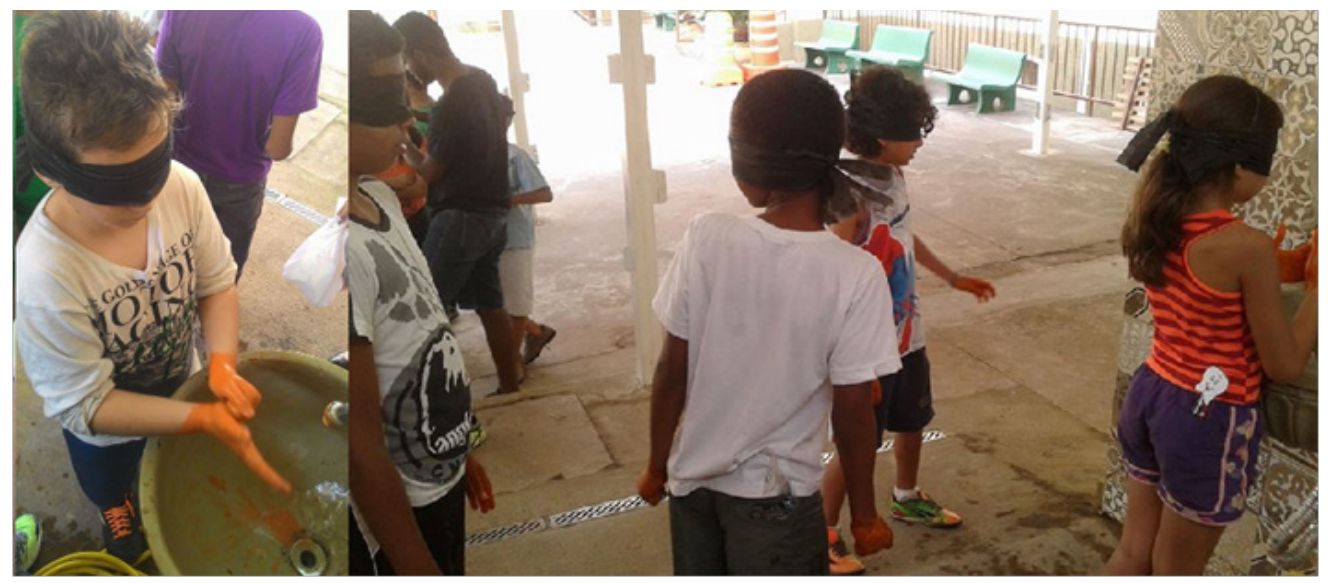

Figura 1

Fotografia da oficina sobre técnica de higienização das mãos.

Fonte: Fotografia do projeto "Infância Saudável: Educação em Saúde nas Escolas”, 2016. Fonte: VIEIRA, M. 
Figura 2

Fotografia da oficina sobre higiene pessoal.

Figura 3

Fotografia da oficina sobre higiene bucal.

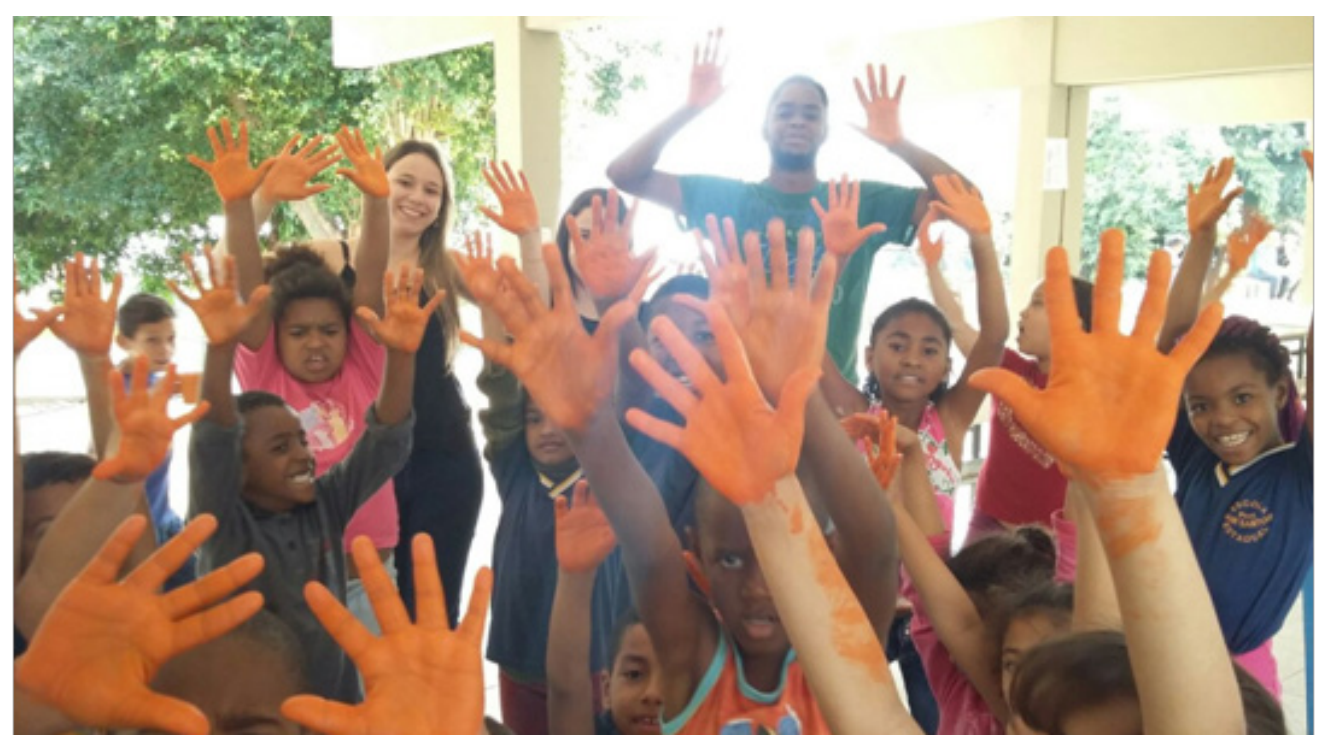

Fonte: Fotografia do projeto "Infância Saudável: Educação em Saúde nas Escolas", 2016. Fonte: VIEIRA, M.

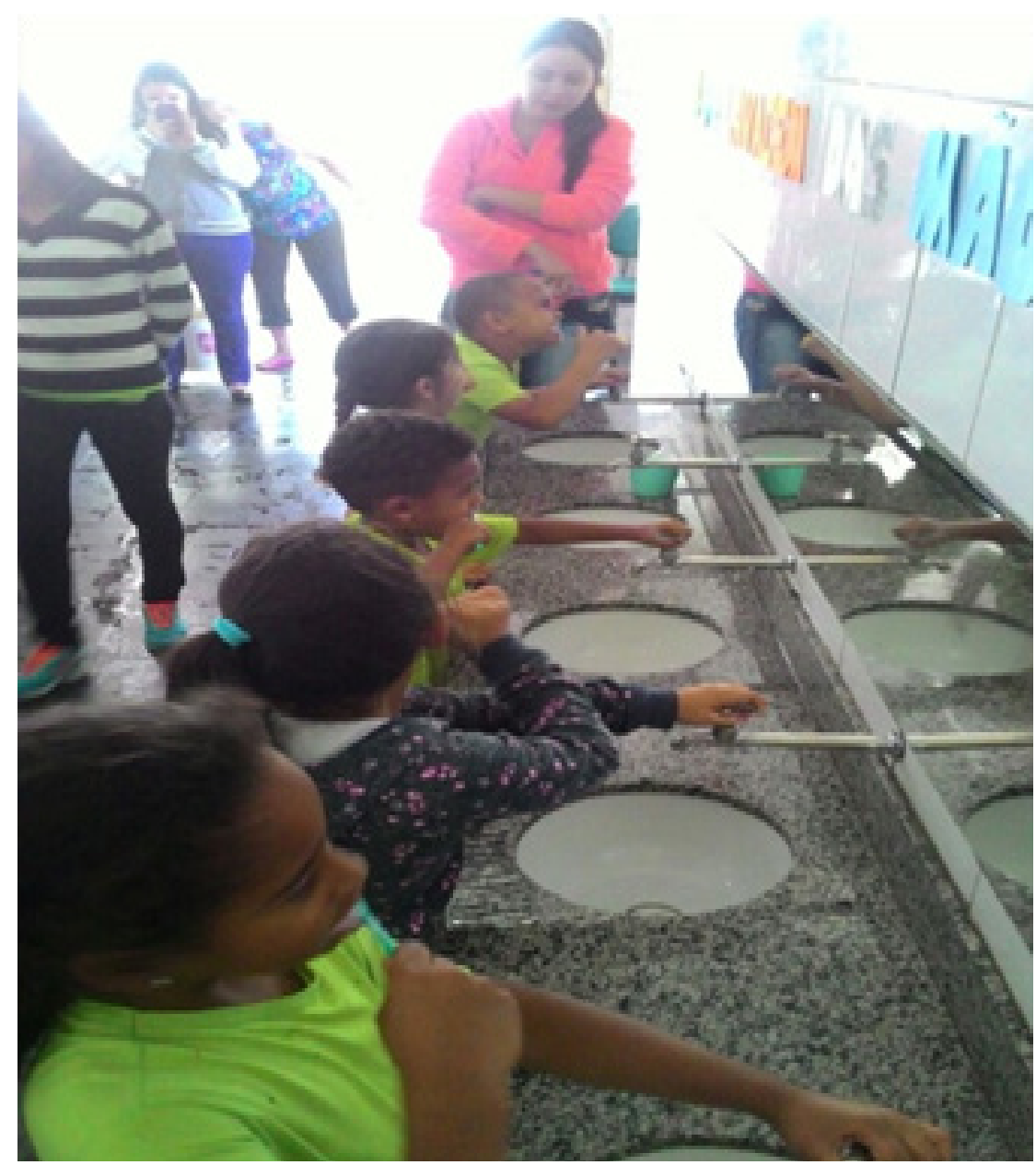

Fonte: Fotografia do projeto "Infância Saudável: Educação em Saúde nas Escolas”, 2016. Fonte: VIEIRA, M. 
A participação dos professores durante as atividades permitiu considerável aproximação entre às temáticas e o cotidiano dos alunos favorecendo assim a inserção de temas ligados à saúde ao cotidiano da escola.

Ações vinculadas às temáticas, destino e acondicionamento do lixo, limpeza e desinfecção de ambientes foram desenvolvidas mediante oficina e roda de conversa com os funcionários responsáveis pelos serviços gerais. A primeira escola contava apenas com cinco profissionais (cozinheiras, jardineiro, faxineiras). Durante a roda de conversa os funcionários relataram a falta de materiais de limpeza favorecendo a precarização das atividades desenvolvidas pelos mesmos (Figura 4). Embora estas ações tenham sido planejadas para ser desenvolvida nas três escolas abrangidas pelo projeto tal ação não foi possível nas demais já que, os funcionários relataram não dispor de tempo.

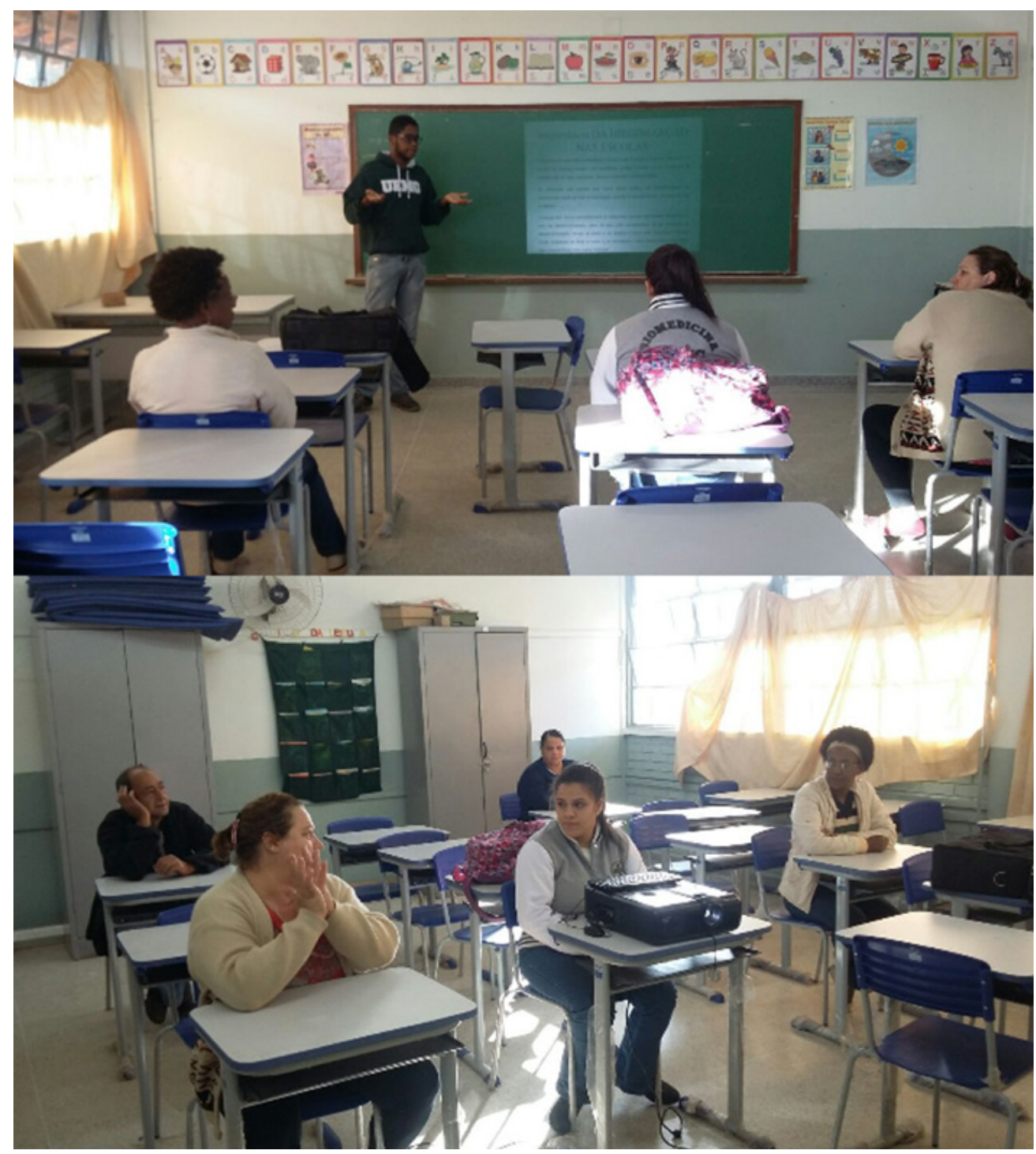

Figura 4

Fotografia da palestra sobre destino e acondicionamento do lixo, limpeza e desinfecção de ambientes.

Fonte: Fotografia do projeto "Infância Saudável: Educação em Saúde nas Escolas”, 2016. Fonte: VIEIRA, M. 
A segunda escola a receber o projeto contava com escolares de 4 a 5 anos, iniciou-se as ações porém, as crianças eram muito jovens e percebeu-se que as mesmas não fixavam o conteúdo. Em uma conversa com a coordenadora optou-se pela finalização do projeto; entretanto, as três temáticas descritas na Tabela 1 foram ofertadas na modalidade de palestra a quatro turmas.

Os escolares da terceira escola tinham entre 8 e 9 anos e as atividades desenvolvidas foram as mesmas daquelas descritas na primeira escola.

Em relação às atividades realizadas nas escolas, estas foram avaliadas constantemente junto aos alunos, professores responsáveis pelas turmas contempladas pelo projeto e direção, com base em discussões informais, a respeito do real aproveitamento das atividades e se estas estavam contemplando as expectativas criadas. Essas avaliações informais eram posteriormente relatadas durante as reuniões semanais e discutidas com toda a equipe de trabalho do projeto. Percebeu-se que as atividades propostas foram assimiladas com êxito entre os escolares de 6 a 9 anos os quais demonstraram interesse sobre os temas propostos, além de terem sido participativos durante a realização das oficinas.

Durante as oficinas os escolares expunham suas dúvidas, relatavam seus hábitos de higiene, eram questionados sobre o conteúdo abordado, e por fim assistiam vídeos para melhor fixação. Observou-se que os mesmos compreendiam de maneira satisfatória os assuntos abordados, não só na teoria, mas também na prática, diante dos resultados observados nas atividades ofertadas ao final de cada tema.

Ressalta-se que, a importância de se trabalhar com escolares de 6 a 9 anos,encontra-se atrelada ao desenvolvimento da necessidade de higiene pessoal e adequação a novos hábitos de vida, pois, é este o período em que a criança desenvolve sua personalidade o que poderá contribuir para aquisição de atitudes mais saudáveis. Atuar com medidas preventivas é mais barato, fácil e eficaz do que trabalhar com medidas curativistas.

Destaca-se ainda que as ações de saúde realizadas nas escolas alteram a dinâmica escolar e que o profissional e os acadêmicos da área da saúde podem não estar preparados para a interação com os estudantes ressaltando assim, a necessidade da participação da comunidade educativa em todas as etapas das ações de saúde nas escolas. Silva e Haddad (2006) apontam importantes desafios para a consolidação da escola como ambiente de promoção da saúde: o processo político-institucional, ruptura do caráter prescritivo, desarticulado e focalizado das ações geralmente desenvolvidas em programas de saúde escolar, transformação de metodologias e técnicas pedagógicas tradicionais, entre outros.

Diante deste contexto, Costa et al. (2013), relata que a efetividade das práticas de educação em saúde no âmbito escolar podem ser facilitada 
quando esse processo passa a ser uma construção coletiva, ou seja, com a participação ativa dos professores. Esses necessitam ser orientados da maneira como implantar a PS em sala de aula. Sendo assim, a PS deve ser abordada de forma contínua e dinâmica, estabelecendo-se como uma importante ferramenta de conscientização.

\section{CONCLUSÃO}

Conclui-se que diante da análise da literatura, percepção das ações desenvolvidas, discussões informais com professores, direção e funcionários que, as ações de educação em saúde na escola, quando de sua integralização e continuidade, podem resultar em uma melhora da saúde dos alunos e em um aprendizado eficaz no que diz respeito à saúde e o desenvolvimento do autocuidado.

REFERÊNCIAS

BRASIL. Ministério da Saúde. Guia de produção e uso de materiais educativos. Brasília: Coordenação Nacional de DST/AIDS, 1998.

COSTA, G.M.C. et al. Promoção de saúde nas escolas na perspectiva de professores do ensino fundamental. Revista Eletrônica de Enfermagem, Goiás, v. 15, n. 2, p. 506-515, 2013.

FRAGA, A. B. et al. Curso de extensão em promoção de saúde para gestores do SUS com enfoque no Programa Academia da Saúde. Brasília: Ministério da Saúde. Secretaria de Vigilância em Saúde; Fundação Universidade de Brasília. CEAD/UnB, 2013. 144 p.

GARDANO B.M. et al. Promoção da saúde e as escolas: como avançar. Revista Brasileira em Promoção da Saúde, Fortaleza, v. 26, n. 3, p. 307-308, 2013.

LIBERAL, E.F.et al. Projeto Saúde na Escola: uma iniciativa bem sucedida de educação em saúde nos CIESPS do estado Rio de janeiro. Rio de Janeiro: UFRJ. 8p, 2002. Disponível em: <http://www.prac.ufpb.br/anais/ Icbeu_anais/anais/saude/cieps.pdf.>. Acesso em: 12 mar. 2016. 
NESTI, M. M. M.; GOLDBAUM, M. As creches e pré-escolas e as doenças transmissíveis. Jornal de Pediatria, Rio de Janeiro, v. 83, n. 4, p. 299312. 2007.

OLIVEIRA, H. M.; GONÇALVES, M. J. F. Educação em saúde: uma experiência transformadora. Revista Brasileira de Enfermagem, Brasília, v. 57, n. 6, p. 761-763, 2004.

SÃO PAULO. Prefeitura Municipal. Manual de boas práticas de higiene e cuidados com a saúde para Centros de Educação Infantil. São Paulo: Secretária Municipal de Saúde, 2008.

SILVA, J. A. A.; HADDAD, F. Escolas promotoras de saúde: experiências do Brasil. Brasília: Ministério da Saúde; Organização Pan-Americana da Saúde, 2006.

SOUZA, M. M. A. et al. Promoção de comportamentos saudáveis em pré -escolares. Revista Brasileira em Promoção da Saúde, v. 26, n. 3, p. 387-395, 2013.

VALADÃO, M. M. Saúde na escola: um campo em busca de espaço na agenda intersetorial. Tese (Doutorado). Universidade de São Paulo - Faculdade de Saúde Pública. São Paulo, 2004.

\section{AGRADECIMENTOS}

Universidade do Estado de Minas Gerais - UEMG. Programa de Apoio à Extensão PAEx/2016 pela concessão de bolsas de extensão aos acadêmicos.

Data de recebimento: 20 de março de 2017.

Data de aceite para publicação: 22 de maio de 2017. 